\title{
Hatay ili şimşir alanlarında yeni bir zararl, Cydalima perspectalis (Walker, 1859) (Lepidoptera: Crambidae)
}

\section{A new pest in Hatay province boxwood areas, Cydalima perspectalis (Walker, 1859) (Lepidoptera: Crambidae)}

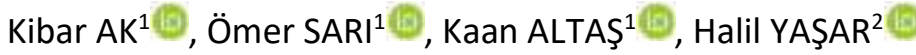 \\ ${ }^{1}$ Karadeniz Tarımsal Araştırma Enstitüsü, Samsun \\ ${ }^{2}$ Alata Bahçe Kültürleri Araştırma Enstitüsü Müdürlüğü, Mersin
}

\section{Eser Bilgisi / Article Info}

Araştırma makalesi / Research article DOI: 10.17474/artvinofd.893012

Sorumlu yazar / Corresponding author

Ömer SARI

e-mail: omer.sari61@hotmail.com

Geliș tarihi / Received

08.03.2021

Düzeltme tarihi / Received in revised form

20.04.2021

Kabul Tarihi / Accepted

20.04.2021

Elektronik erişim / Online available

12.05.2021

\section{Anahtar kelimeler:}

Buxus sempervirens

Buxus balearica

Cydalima perspectalis

Hatay

Dörtyol

\section{Keywords:}

Buxus sempervirens

Buxus balearica

Cydalima perspectalis

Hatay

Dörtyol

\begin{abstract}
Özet
Türkiye'de yaklaşık bin hektarlık bir yayılış alanına sahip olan Buxus sempervirens (şimşir), Hatay ilinin önemli bitki türlerinden biridir. Hatay ilinde önemli bir doğal şimşir alanı da Dörtyol ilçesidir. Son yıllarda bölgede şimşirlerde görülen kurumanın kaynağı araştırılmış ve Cydalima perspectalis olduğu tespit edilmiştir. Daha önce bu bölgede yayılışı tespit edilmemiş olan bu tür Kozlu Dere mevkiinde bu çalışmayla literatüre girmiştir. Çalışma yapılan alanda zarar görmüş bitki örnekleri alınarak laboratuvara getirilmiş, kültür kutularında kültüre alınan zararlı ile bulaşık bitki artıklarından erginler elde edilmiş ve teşhisi yapılmıștır. Zararlının larva erginlerinin morfolojik ölçüm ve karakteristik özellikleri verilmiştir. $C$. perspectalis'in larvalarının bölgedeki şimşirlerin yapraklarıyla beslendikleri, sürgünlerin kabuklarını kemirerek kambiyum tabakasına zarar verdikleri tespit edilmiştir. Şimşir alanları için önemli bir zararlıya karşı yapılan bu çalışma C. perspectalis'in Hatay ilindeki şimşir alanlarında zararlı olduğunu bildiren ilk çalışmadır. Ayrıca çalışma ile zararıının bu bölgedeki önemi ortaya konulmuş ve mücadelesine yönelik öneriler verilmiştir.
\end{abstract}

\begin{abstract}
Buxus sempervirens, one of the boxwood spices in Turkey, have a natural population of approximately thousand hectares. Hatay province is an important province in terms of natural boxwood areas. The source of drying seen in boxwoods in the region in recent years has been investigated and it has been determined that Cydalima perspectalis. This species, whose distribution in this region has not been determined before, has entered the literature with this study in Kozlu Dere locality. Samples of damaged plants were taken in the study area and brought to the laboratory, and adults were obtained from the pest taken in culture in culture boxes and from contaminated plant residues, and the diagnosis was made. Morphological measurements and characteristic features of the pest's larval adults are given. It has been determined that the larvae of $C$. perspectalis feed on the leaves of the boxwood in the region and damage the cambium layer by gnawing the shells of the shoots. This study conducted against an important pest for boxwood fields is the first to report that $C$. perspectalis is a pest in Hatay province's boxwood fields. Besides, the importance of the pest in this region was revealed with the study, and suggestions were given for its fight.
\end{abstract}

\section{Giriş}

Şimşir, ülkemizde orman alanlarında doğal olarak yetişen, odunu ve sürgünleriyle ülke ekonomisine katkı sağlaması ve peyzaj alanlarında tercih edilmesi nedeniyle önemli bir yere sahiptir. Dünyadaki 105 şimşir türünden, ülkemizde Anadolu Şimşiri (Buxus sempervirens) Denizli, Kahramanmaraş, Osmaniye, Kocaeli, Bolu, Karabük, Bartın Kastamonu, Trabzon, Rize ve Artvin illerinde bulunurken, Baleric Şimşiri (Buxus balerica Lam.) Adana, Antalya ve Hatay illerinde bulunmaktadır. Hatay ilindeki Amanos dağlarında Buxus sempervirens yayılış göstermekte, Buxus balerica ise Hatay merkezde SenPiyer kilisesi ve etrafında yayılış göstermektedir (Symmes 1984, Sarı ve Çelikel 2019). Anadolu Şimşiri (B. sempervirens) Türkiye'de genellikle orman alanlarında yaklaşık bin hektarlık doğal popülasyonu bulunmaktadır (Lehtijärvi ve ark. 2017). B. sempervirens ülkemizde park ve bahçelerde peyzaj bitkisi olarak kullanıldığı gibi, saksılı süs bitkisi, her dem yeşil ve de gösterişli yaprakları nedeniyle çiçek buketleri ve çelenklerde dolgu malzemesi olarak kullanılmaktadır (Sarı ve Çelikel 2019). Ayrıca şimşirler oyuncak, havan, kaşık, tarak, tabak, tavla pulu, ağızlık, makine yatakları, mekik, hançer sapları, kutular süs eşyaları gibi alanlarda ve zaman zaman da alternatif tıpta bazı hastalıkların tedavisinde kullanılmaktadır (Baytop 1999, Türkyılmaz 2004).

Dünyada olduğu gibi Türkiye'de de bulunan şimşir türleri çevresel faktörlerin, hastalık ve zararlıların yapmış olduğu 
zararlar sebebiyle genetik erozyona uğramakta ve yok olma tehlikesi ile karşı karşıya kalmaktadır. Ayrıca zararlıların baskısı altında olan şimşir türlerinin önemli zararlılarının Monarthropalpus flavus Lab. (Diptera: Cecidomyiidae), Eurytetranychus buxi Garman (Acari: Tetranychidae), Psylla buxi L. (Hemiptera: Psylloidea) ve Cydalima perspectalis Walker (Lepidoptera: Crambidae) olduğu bildirilmektedir (Salioğlu 2020). Bu zararlılardan C. perspectalis, Asya kökenli bir tür olup, Avrupa'da ilk olarak 2007 yılında Almanya'da ve Hollanda'da tespit edilmiştir (Billen 2007, Van der Straten ve Muus 2010). 2008 yılında Fransa, İsviçre, Avusturya ve İngiltere'de; 2009 'da Avusturya ve Fransa'da (Van der Straten ve Muus 2010); 2010 yılında Romanya'da tespit edilmiştir (lamandei 2010). 2011'de Macaristan'da tespit edildikten sonra Hırvatistan, İtalya, Slovenya, Karadağ, BosnaHersek, İspanya ve Sırbistan'da varlığı rapor edilmiştir (Sáfián ve Horváth 2011, Koren ve Črne 2012, Farina ve Rizzo 2015, Seljak 2012, Hrnčić ve Radonjić 2014, Otero ve Pérez 2014, Ostojić ve ark. 2015, Stojanović ve ark. 2015). Komşularımızda ise ilk olarak 2013 yılında Yunanistan'da, 2014 yılında Bulgaristan'da ve 2015 yılında da Gürcistan'da tespit edilmiştir (Strachinis ve ark. 2015, Matsiakh ve ark. 2016, Arnaudov ve Raikov 2017). Ülkemizde ise ilk olarak 2011 yılında İstanbul'da ki park ve bahçelerde, 2015 yılında Düzce'de ve Artvin'de, 2016 yılında ise Bartın'da varlığı tespit bildirmiştir (Hizal ve ark. 2012, Öztürk ve ark. 2016, Göktürk 2017, Kaygın ve Taşdeler 2018, Yıldız ve ark. 2018).

Zararlı yaklaşık olarak yılda beş km mesafeye kadar uçabildiğinden zarar yapma kapasitesinin yüksek olduğu ve farklı konukçularda beslenebileceği bildirilmiştir (Matosevic 2013). Kaygın ve Taşdeler (2019), zararlının ana konukçusunun şimşir olduğunu bildirmiştir. Fakat CABI (2020) tarafından larvaların birçok Buxus türlerinde zarar yaptığı bildirilmektedir. Van der Straten ve Muus (2010), Bunescu ve Florian (2016a), Avrupa'da sadece Buxus sempervirens, B. microphylla var. insularis, Buxus sinica, Buxus microphylla şimşir türlerinde zararlı olduğunu bildirmiştir. Santi ve ark. (2015), Bunescu ve Florian (2016b), Çin ve Japonya'da japon süpürgesi (Pachysandra terminalis), çoban püskülü (Ilex purpurea) ve taflan (Euonymus alatus ve Euonymus japonicus) ve Portakal çiçekli yasemin (Murraya paniculata) bitkilerinde zararı olduğunu bildirilmektedir. Ayrıca nadir de olsa Rubus spp., Ruscus colchicus, R. aculeatus, Eriobotrya japonica, Acer campestre, Fraxinus excelsior, Rubus fruticosus ve Smilax excelsa türleri üzerinde de zarar yaptığı tespit edilmiştir (Trokhov ve Kaurova 2015, Matsiakh ve ark. 2018).

Bu çalışmada ise TAGEM tarafından desteklenen Şimşir (Buxus sempervirens L. ve Buxus balerica Lam.) seleksiyonu ve çoğaltılması projesi kapsamında yapılan arazi ve bitki toplama çalışmaları sırasında Karadeniz ve Marmara Bölgelerinde önemli tahribata neden olan $C$. perspectalis'in Akdeniz Bölgesinde de görülmesi sonucu ele alınmıştır. Yapılan bu çalışma ile şimşir için önemli bir doğal alan olan Amanos dağlarındaki şimşir ormanlarında önemli bir şimşir zararlısı incelenmiştir.

\section{MATERYAL VE METOT}

Bu çalışmanın ana materyalini, Hatay ili, Dörtyol ilçesinde bulunan, şimşirlerin kurumasına neden olan ve istilacı bir tür olan Cydalima perspectalis oluşturmaktadır. Diğer materyaller olarak kültür kutuları, mikroskop ve fotoğraf makinesi kullanılmıştır.

Bu çalışmada zararlının biyolojisi ve pupa dönemiyle ilgili çalışma yapılmamış, araziden elde edilen bulaşık bitkiler üzerinde zarar görmüş sürgün ve yapraklarda tespit edilen larvaların morfolojik ölçümleri yapılmış ve kültüre alınarak erginler elde edilmiştir. Larvalarda olduğu gibi erginler üzerinde de morfolojik ölçümler 10 birey üzerinden yapılmıştır.

Bu çalışma, 2020 yılı son baharında Hatay ili, Dörtyol ilçesindeki Kozludere mevkii şimşir ormanlarında bulunan zarar görmüş $B$. sempervirens üzerinden zararlı ile bulaşık bitki örnekleri toplanmış, fotoğrafları çekilmiş ve Samsun Karadeniz Tarımsal Araştırma Enstitüsü Entomoloji laboratuvarına getirilmiştir. Örnekler $50 \times 50 \mathrm{~cm}$ ebadındaki kafesli kültür kutularında kültüre alınarak erginler elde edilmiştir.

Kültür kafeslerinde kültüre alınan örneklerden çıkan erginlerin preperasyonları yapılarak teşhise hazır hale getirilmiş ve teşhisleri yapılmıştır. Ayrıca larva ve erginler üzerinde ölçümler yapılmıştır.

Araştırma alanı olarak çalışma şimşir bitkisinin doğal olarak yayılış gösterdiği Hatay ili, Dörtyol ilçesindeki Kozlu Dere mevkiinde yürütülmüştür (Şekil 1). 


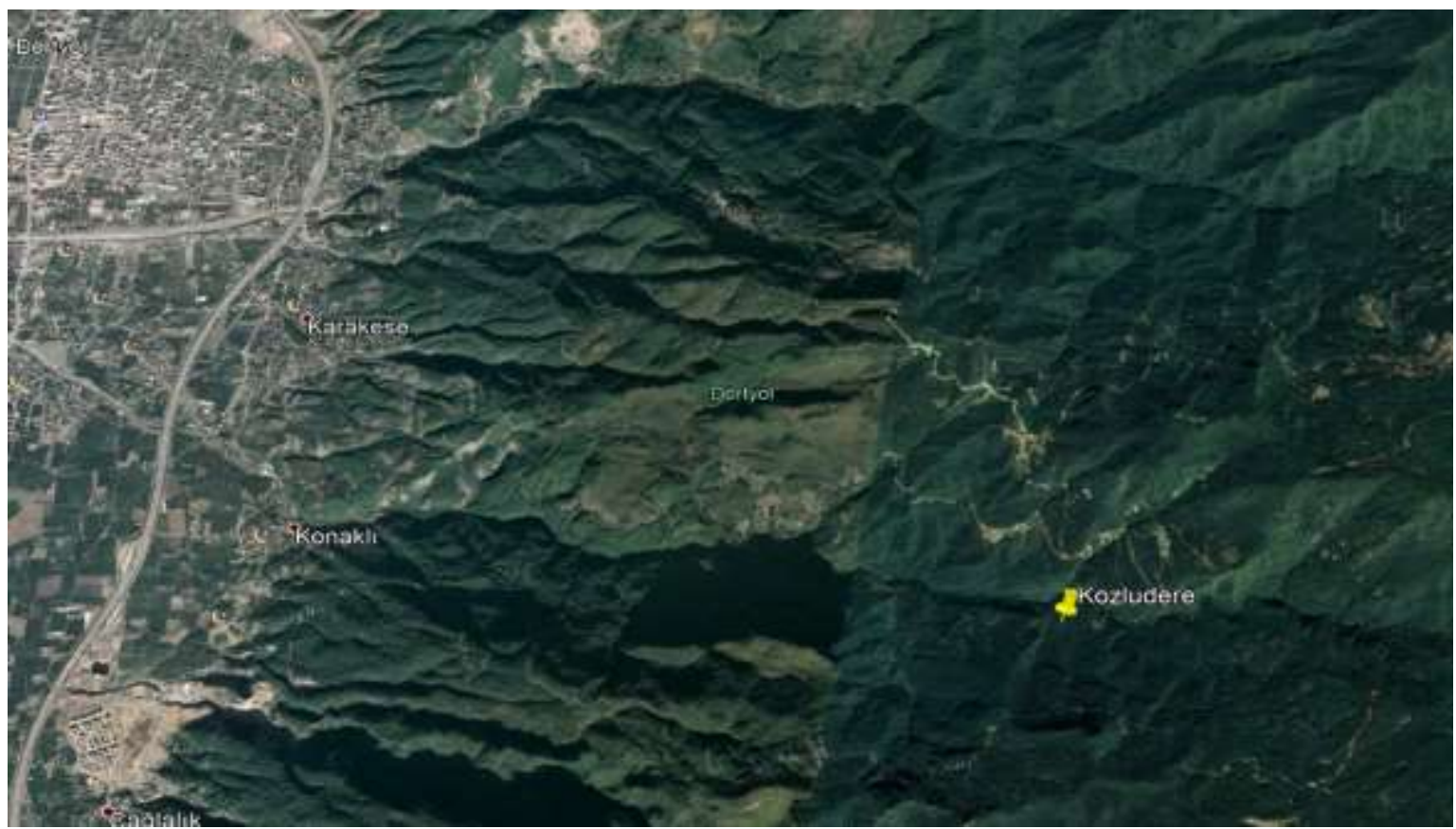

Şekil 1. Çalışma yapılan alan (Hatay, Dörtyol, Kozludere mevkii)

\section{BULGULAR VE TARTIŞMA}

Yapılan teşhis sonucunda B. sempervirens' de zarar yapan böceğin $C$. perspectalis olduğu belirlenmiştir (Şekil 2 a ve b). Zararlının larva döneminde yaprak ve sürgünlerde beslenerek zarar yaptığı bilinmektedir. C. perspectalis bu çalışma ile Hatay ilinden ilk defa rapor edilmiştir. Çalışma yapılan bölgede $B$. sempervirens'in popülasyonu üzerinde en önemli tehdidin C. perspectalis olduğu belirlenmiştir.

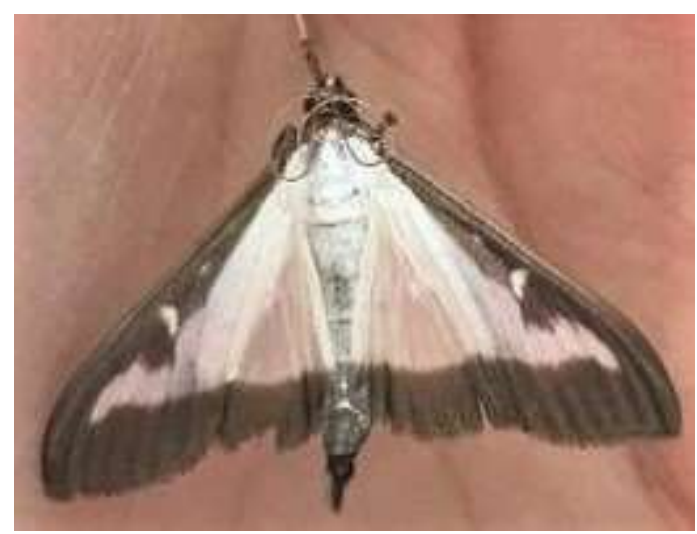

a
C. perspectalis Avrupa'da, Buxus sp. Türlerinin yayılış gösterdiği ormanlık alanlarda ciddi bir tehdit olduğu kabul edilmektedir. Gerek park ve bahçelerde, gerekse doğal alanlardaki ağaçların etkilenmemesi için, zararlıyı tanımaya yönelik çalışmalar yapılmış ve bu çalışmalara dayanılarak mücadelesi için önerilerde bulunulmuştur. Zararı ile ilgili yapılan çalışmalarda C. perspectalis'in 4 biyolojik döneminin olduğu (yumurta, larva, pupa, ergin), zararlının beyaz ve kahverengi olmak üzere iki formda bulunduğu belirlenmiştir (Kaygın ve Taşdeler 2019).

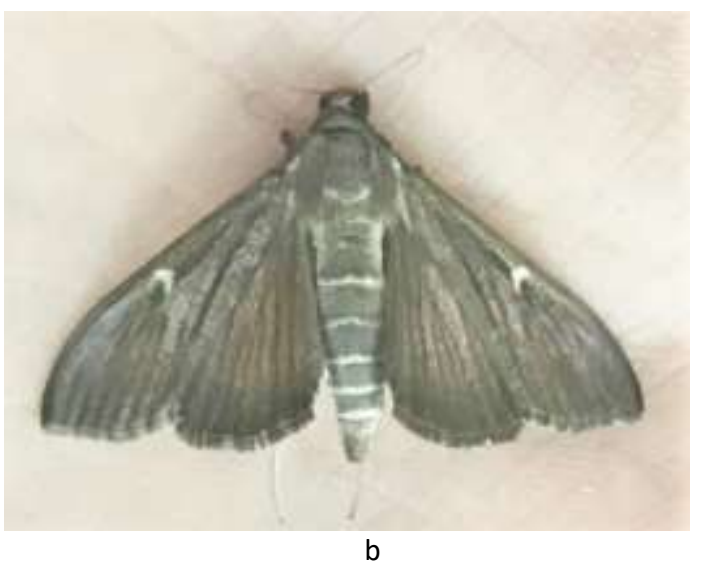

Şekil 2. Cydalima perspectalis ergininin beyaz formu (a) ve kahverengi formu (b)

Székely ve ark. (2011), Leuthardt ve Baur (2013), Oltean ve ark. (2017), Kaygın ve Taşdeler (2019), zararlının yumurtalarının yaklaşık $1 \mathrm{~mm}$ çapında ve şimşir yapraklarının altında yassı olarak gruplar halinde bulunduğunu bildirmektedir (Şekil 3). Larvalar en fazla 4 $\mathrm{cm}$ uzunluğunda oldu, uzunlamasına kalın, siyah ve ince beyaz çizgili yeşil renkte olduğu, vücudun sırt tarafında beyazımsı siyah noktalar bulunduğu belirtilmektedir. Bu çalışmada da larva boyunun $3.5-4 \mathrm{~cm}$ ve literatürlere benzer renk karakterinde olduğu belirlenmiştir (Şekil 4). 


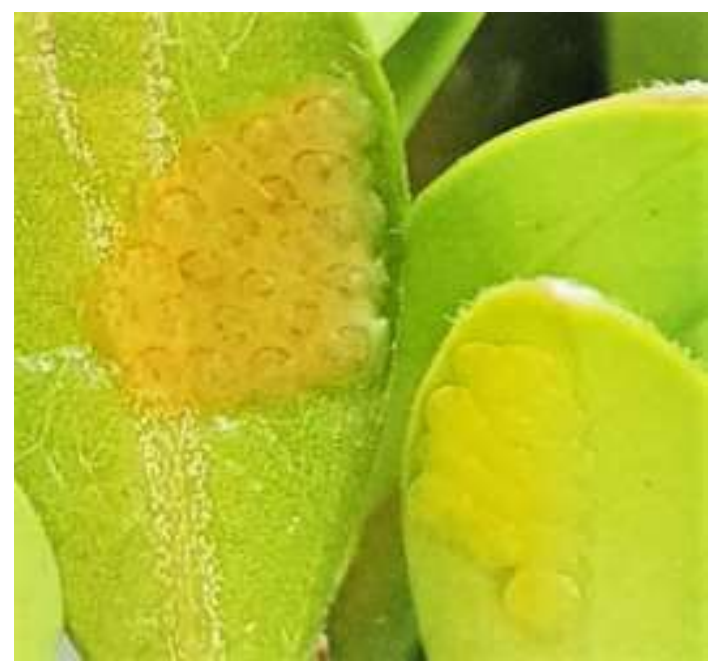

Şekil 3. Cydalima perspectalis'in yumurtası

Bu çalışmada da larvaların yaprak ve sürgünler üzerinde beslenerek kurumaya neden olduğu sürgün uçlarında yaprakları bir araya getirerek koza ördüğü tespit edilmiştir.

Zararlının biyolojik dönemine ait ülkemizde yapılan bazı çalışmalar değerlendirildiğinde; İstanbul'da 2011 yılı 20 Haziran - 30 Temmuz tarihleri arasında yapılan arazi gözlemlerinde zararlının larvalarının yaptığı zarar belirlenmiş ve ilk erginlerinin 30 Temmuz'da görüldüğü bildirilmiştir (Hizal ve ark. 2012). Artvin'de yapılan çalışmada ise ilk larvaların 20 Mart 2018'de Buxus sempervirens üzerinde bulunduğunu, larvaların obur beslenerek yaprakları yediklerini ve sadece dal kısımlarının kaldığı bildirilmiştir. Ayrıca pupanın yapraklarda oluştuğunu ve $C$. perspectalis pupaları yapraklar arasında gizlendiği rapor edilmiştir. Erginlerin ise, dış kenarda koyu kahverengi bir bant ile çoğunlukla beyaz kanatlara sahip olan türlerin en yaygın varyantı gözlemlenmiştir. Yumurtadan yeni çıkan larvalar sadece yaprakların altından beslendiği belirlenmiştir (Akıncı ve Kurdoğlu 2019).

$\mathrm{Bu}$ çalışma Şimşir (Buxus sempervirens L. ve Buxus balerica Lam.) Seleksiyonu ve Çoğaltılması projesi kapsamında yapılan arazi ve bitki toplama çalışmaları sırasında Akdeniz Bölgesinde yapılan çalışmalar esnasında zararlının görülmesiyle Kozlu Dere mevkiinde larva dönemindeki veriler değerlendirilmiştir.

$\mathrm{Bu}$ çalışmada $C$. perspectalis erginlerinin beyaz renkte olan kanatlarını çevreleyen kahverengi çizgilerden oluştuğu, ön kanadın anal kısmının kenarında kahverengi renkte bir bant ve arka kanatlarda kahverenginde geniş bir kenar şeridin olduğu belirlenmiştir. Székely ve ark. (2011), Kaygın ve Taşdeler (2019), C. perspectalis'in kanat

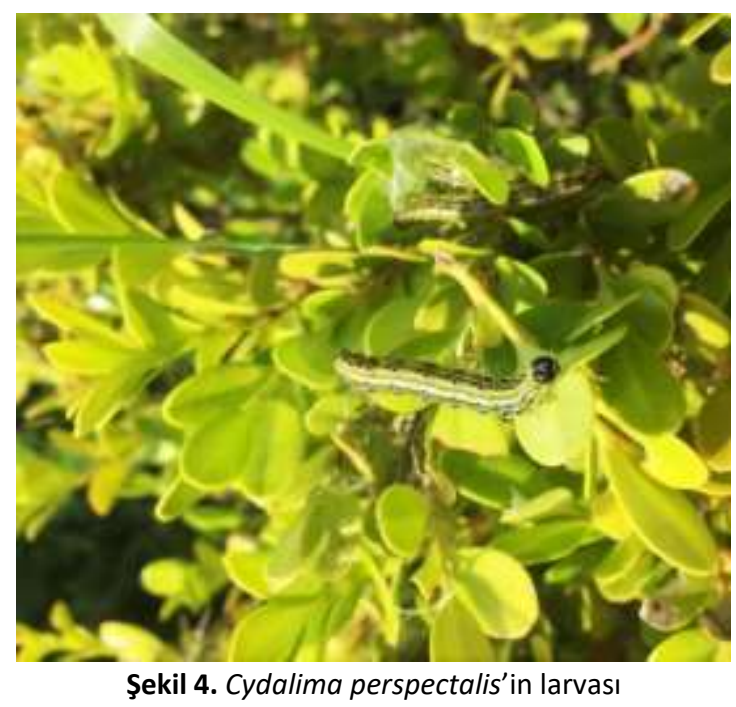

açıklığının ise 3.5-4 cm olduğunu, zararlının Avrupa Crambidae'ları arasında büyük bir tür olduğunu, çoğunlukla geceleri aktif olduğu ve ancak gündüz de bulunabildiğini bildirmişlerdir.

C. perspectalis hızlı yayılmasından dolayı, son yıllarda biyolojisi ile ilgili birçok çalışmaya konu olmuştur. Genel olarak iklim değerleriyle değişmekle birlikte $C$. perspectalis'in döl sayısının yılda 1-5 arasında değiştiği rapor edilmiştir (She ve Feng 2006). Avrupa'da biyolojisi ile ilgili yapılan çalışmalara göre Almanya'da yılda iki nesil verdiği bildirilmektedir (Korycinska ve Eyre 2009, Leuthardt ve ark. 2010, Sage ve Karl 2010, Van Der Straten ve Muus 2010, Korycınska ve Eyre 2011). Türkiye'de zararlının biyolojisi ile ilgili bir çalışmada, Düzce ilinde zararlının döl sayısı belirtilememekle birlikte, 2015 yılı nisan-mayıs aylarında gözlenen birinci nesil larvalarını takiben ikinci nesil larvalarının temmuz ayına kadar önemli zararlara neden olduğu bildirilmiştir (Kaygın ve Taşdeler 2019). Salioğlu (2020), C. perspectalis'in Bartın ilinde 3 döl verdiğini, Akdeniz bölgesinde ise daha fazla döl verebileceğini, Artvin ilinde ise 2 döl verdiğini bildirmiştir. Bu çalışma ile zararlının daha önce tespit edildiği Karadeniz bölgesinde 2-3 döl verirken Akdeniz bölgesinde ise daha fazla döl verebileceği ve bu nedenle daha fazla zarar yapacağı düşünülmektedir.

Yapılan bu çalışmada larvalarının şimşirlerin yaprakları ile beslendiği tespit edilmiştir. Bazı bitkilerin ise larva zararı nedeniyle sadece dallarının kaldığı, bitkilerin çalı şeklinde kurudukları belirlenmiştir. Nitekim yapılan birçok araştırmada, C. perspectalis tarafından zarar görmüş şimşir bitkilerinin yapraklarını tamamen yiyerek bitkileri öldürebildiği bildirilmiştir (Krüger 2008, Sigg 2009, Sage ve Karl 2010, Hızal ve ark. 2012) (Şekil 5). 

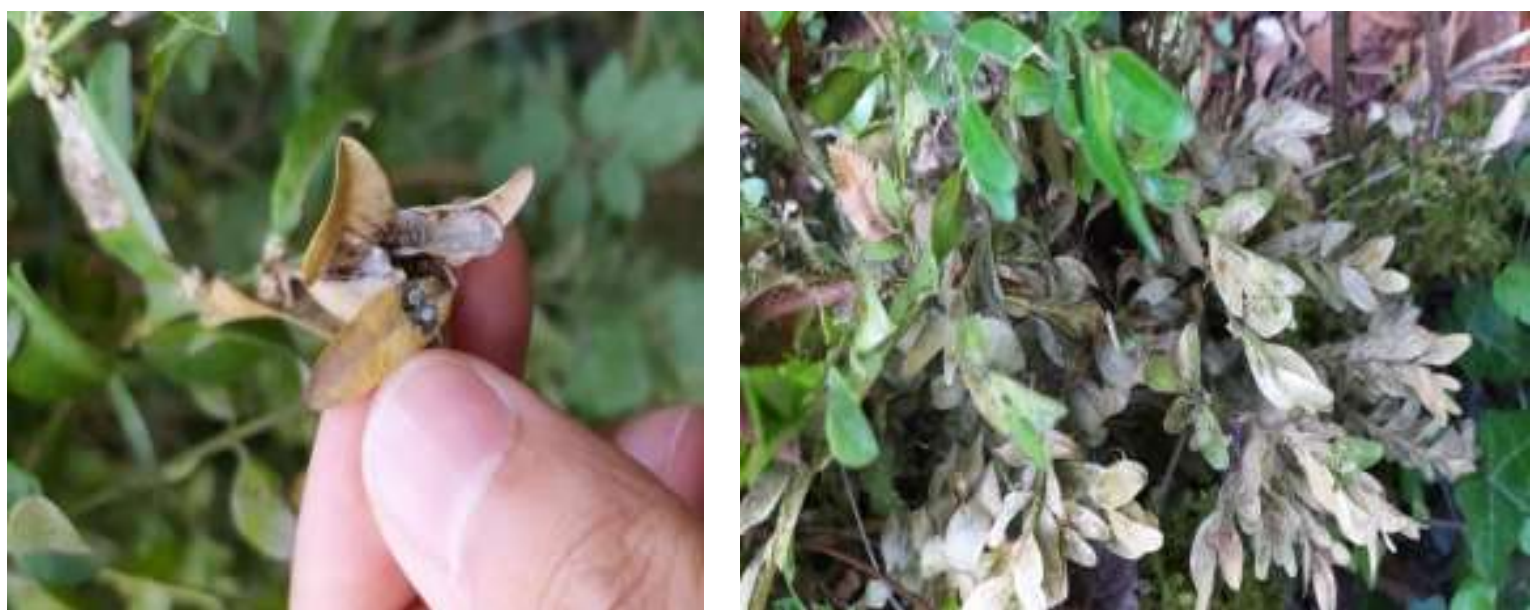

Şekil 5. Cydalima perspectalis'in şimşir bitkisine verdiği zarar.

C. perspectalis, 2008'den 2011'e kadar EPPO (European and Mediterranean Plant Protection Organization)'nun uyarı listesinde yer almıştır (Plant ve ark. 2019). C. perspectalis'i Avrupa ve Kafkasya'daki şimşir ormanlarında ciddi bir zararlı olarak değerlendiren Matsiakh ve ark. (2018), Güney Rusya'da larvaların yoğun zararını kaydederek, Gürcistan'daki doğal Buxus colchica (Synonym: Buxus sempervirens L.) ormanlarının ciddi bir zararlısı olduğunu bildirmiştir. Plant ve ark. (2019) Almanya'da ülkenin en büyük ormanı olan GrenzachWhylen Doğa Koruma Alanı'ndan 2009 ve 2010 yıllarında zararlının larvaları tüm şimşir ağaçlarına saldırarak ağaçlardaki yaprakların \% 90'dan fazlasını dökerek ağaçların \% 27'sinin tüm yapraklarını dökmesine neden olduğunu bildirmiş, 2012 yılına kadar kabukları kemirilen ve tamamen yaprakları yenen ağaçların öldüğü bildirilmiştir. Bunun sonucunda bu ormandaki ekosistemde $B$. sempervirens'in yerini alan yeni bitki örtüsü ile değişmeye başladığı gözlemlenmiştir. Öztürk ve ark. (2016), Artvin ilinde C. perspectalis'in zarar oranını belirlenmiş ve incelenen şimşir ağaçlarının sadece \% 4.4'ü hasarsız, \% 42.2'si zayıf veya orta hasarlı olduğunu bildirmiştir. Bu sonuçlar, C. perspectalis'in zarar yaptığı şimşir ağaçları üzerinde önemli bir zararlı etkiye sahip olduğunu göstermektedir. Bu çalışmada da zararlının Akdeniz Bölgesinde de bulunduğu tespit edilmiş ve bulunduğu alanda şimşir bitkisinin en önemli tehdidi olduğu gözlemlenmiştir. Bunun nedeninin bölgenin daha sıcak ve vejetasyon süresinin uzun olmasından dolayı diğer bölgelere göre daha fazla döl verebileceğinden kaynaklanmaktadır. Tespit edilen alanlarda dal ve sürgünlerin kabuklarını kemirerek sürgünlerin kurumasına neden olduğu, yapraklarda beslenerek yaprakları kuruttuğu ve yanmış bir görüntüye neden olduğu belirlenmiştir.
C.perspectalis ile dünyada birçok mücadele metodu kullanılmaya çalışarak zararı azaltılmaya çalışıımaktadır. Doğu Asya'da nematodlar (Steinernema carpocapsae), çiftleşmeyi engelleyen feromonlar ve pestisitler ile kombinasyon oluşturarak mücadele edildiği bildirmektedirler (Choo ve ark. 1991, Lee ve ark. 1996, Zhou ve ark. 2005, Kawazu ve ark. 2007, Korycinska ve Eyre 2011). Doğal düşmanlardan, konukçuya özgü olmayan çeşitli parazitoidler ve kuşlar olduğu belirlenmiştir (Nacambo ve ark. 2014, Strachinis ve ark. 2015). Ancak, kuşların larvalarda bulunan yüksek seviyedeki toksik alkaloidler nedeniyle sadece küçük bir değere sahip olduğu bildirmiştir (Leuthardt ve Baur 2013). Bununla birlikte, Martin ve ark. (2018), Fransa'da zararl ile istila edilmiş bir alana kuşların yerleştirilmesi ile yapılan çalışmada, kuşların larvaları yemeyi öğrenmeye başladığını ve toksisitenin yavruları üzerinde kısa vadede hiçbir etkisinin olmadığını tespit etmiştir. Entomopatojenlerden Bacillus thuringensis var. kurstaki bakterisinin bir dizi alt türünden ekstrakte edilen toksinler Lepidopter larvalarına karşı yıllardır kullanılmakta olup, $C$. perspectalis'e karşı kullanılabileceği bildirilmiştir. Böcek patojeni virüslerden larvalara karşı Anagrapha falcifera nükleopolihedrosis virüsünün etkisi (AnfaNPV) laboratuvar çalışmalarıyla belirlenmiş, ancak arazı çalışmaları ile desteklenmesi gerektiği bildirilmiştir (Rose ve ark. 2013). Bu çalışmadan elde edilen gözlem ve verilere dayanılarak zararının doğal düşmanlarının belirlenmeli, varsa bunların popülasyonlarını korumaya ve artırmaya yönelik tedbirler alınmalı ve zararının lokalize olmuş alanlarda benzer zararlılara karşı kullanılan biyolojik preparatlar ile larva dönemlerinin başlangıcında mücadele edilmelidir. 
Kimyasal mücadelede ise, park ve bahçeler içinde pestisit kullanımı çok dikkatli yapılmalıdır. Pestisit kullanımı Entegre Mücadelede Yönetimi içinde en son kullanılan mücadele olup, neonikotinoidler kullanarak ilaçlama yapılmaktadır. Mevcut pestisitlerin hiçbiri $C$. perspectalis'e özgü olmadığından diğer hedef olmayan çalılıları da öldürebilmektedir. Bu nedenle tek seçenek olarak kabul edilse bile bunlar çok dikkatli uygulanmalıdır. Feromon tuzaklar ise ticari olarak mevcut olup giderek daha da kullanımı yaygınlaşmaktadır. Ancak kitlesel amaçlı kullanımda yalnızca erkek bireyleri çekmesi nedeniyle zararlıya karşı etkili bir mücadele için kullanılamamaktadır (Plant ve ark. 2019).

Ülkemiz, şimşir türleri açısından ayrı bir yere sahiptir. Anadolu Şimşiri (B. sempervirens L.) ve Baleric Şimşiri ( $B$. balerica Lam) dışında, ülkemizde yayılış göstermeyen ancak ticari olarak Osmanlı şimşiri (Buxus microphylla) olarak adlandırılan, küçük yapraklı şimşir de zararının konukçuları arasındadır. Özellikle Akdeniz belgesinde tespit edilen zararlı bu alandaki ormanların şimşir varlığı için çok önemli bir tehdit durumundadır. Bunun nedeni ise bu bölgedeki döl sayısının fazla olmasından kaynaklanmaktadır. Herhangi bir zararlının döl sayısı ne kadar fazla olursa zararının o ölçüde artacağı bilinmektedir. Kaygın ve Taşdeler (2019)'de şimşirin yayılış alanı içinde olan Akdeniz Bölgesi'nde bu türün daha fazla döl verme potansiyeli olduğunu bildirmektedir. Yapılan çalışmalara ve literatürlere göre $C$. perspectalis'in bilhassa ülkemizde doğal olarak yayılış gösteren şimşirlerimizin önemli bir kısmının yok olmasına sebep olmuştur. Kalan şimşir ormanlarımız da çok ciddi olarak tehdit altındadır. Zararıııın çok hızlı çoğalma ve yayılma özelliğine sahip olduğu göz önüne alındığında diğer bölgelerde yaptığı zararın, Akdeniz Bölgesinde de çok hızlı bir şekilde yapabileceği sonucunu göstermektedir. Şimşir alanlarının bulunduğu bölgelerde, yöre halkının geçim kaynaklarından birinin, şimşirden elde edilen ürünler olması, bu zararlıya karşı hassasiyeti arttırmaktadır. Bu nedenle Hatay ve çevre il ve ilçelerdeki park ve bahçelerde kullanılan şimşir türleri ile bu türlerin bulunduğu orman alanlarında zararlının populsayonunun periyodik olarak takip edilmesi, ithal edilen bitkisel materyallerdeki denetimlerin daha dikkatli yapılması, yerli üretimin arttırılması, doğal şimşir türlerimizin çoğaltılması üzerine çalışmaların teşvik edilmesi, mücadele alanında gerekli önlemlerin zamanında alınması ve mücadelenin ciddi bir şekilde yürütülmesi gerekmektedir.
Sonuç olarak, bölgemizin önemli şimşir plantasyonlarında yayıldığı bilinen ve bu çalışma ile Akdeniz Bölgesinin önemli bir şimşir alanının olduğu Hatay ili, Dörtyol ilçesindeki Kozludere mevkiindeki belirlenen bu zararlının yayılışı ve popülasyonu takip edilerek sorumlu kurum ve kuruluşlar tarafından gerekli mücadeleye başlanılmalıdır. Ayrıca bu çalışma ile zararlıya karşı mücadelede öneriler olarak;

1. Zararlıya karşı mücadelede Entegre Mücadele yöntemi benimsenmeli ve tüm mücadele yöntemleri entegre edilerek uygulanmalı,

2. Zararlının bulunduğu ve yayıldığı alanlar belirlenerek popülasyonun düşük olduğu yerlerde ilk dölden başlayarak mekaniksel mücadele yapılmalı,

3. Zararlıya karşı kimyasal veya organik preparatlar ile yapılacak mücadelede öncelikle feromon tuzaklar ile ergin çıkışları takip edilmeli, ergin çıkışını takiben yumurta ve larva çıkışları takip edilerek mücadeleye başlanmalı,

4. Zararlının yoğun olduğu alanlar dışında kalan alanlarda doğal düşman varlığı dikkate alınarak kimyasal mücadele yerine mekanik mücadele tercih edilmelidir.

\section{KAYNAKLAR}

Akıncı HA, Kurdoğlu O (2019) Damage level of Cydalima perspectalis (Lepidoptera: Crambidae) on naturally growing and ornamental box populations in Artvin, Turkey. Kastamonu Üniversitesi Orman Fakültesi Dergisi, 19(2), 144-151.

Arnaudov V, Raikov S (2017) Box tree moth-Cydalima perspectalis (Walker, 1859) (Lepidoptera: Crambidae), a new invasive pest for the bulgarian fauna.". XXII Savetovanje o biotehnologiji". Zbornikradova, 1, 453-456.

Baytop T (1999) Türkiye'de Bitkiler ile Tedavi, Nobel Tıp Kitabevleri, İstanbul, 393-394.

Billen W (2007) Diaphania perspectalis (Lepidoptera: Pyrallidae)-a new moth in Europe. Mitteilungen der Entomologischen Gesellschaft Basel, 57(2/4), 135-137.

Bunescu H, Florian T (2016a) The Box Tree Moth, Cydalima perspectalis Walker (Lepidoptera: Crambidae: Spilomelinae) a New Invasive Species in Cluj Area (Romania) ProEnvironment/ProMediu, 9(25), 62-66.

Bunescu H, Florian T (2016b) Studies Concerning the new Invasive Species, Cydalima perspectalis Walker (Box Tree Moth) in Cluj Area (Romania) ProEnvironment/ProMediu, 9(26), 142-151.

CABI (2020) https://www.cabi.org/isc/datasheet/118433 (29.12.2020)

Choo HY, Kaya H K, Lee SM, Kim TO, Kim JB (1991) Laboratory evaluation of entomopathogenic nematodes, Steinernema carpocapsae and Heterohabditis bacteriophora against some forest insect pests. Korean Journal of Applied Entomology 30(4): $227-232$.

Farina P, Rizzo D (2015) Regione Toscana, La Piralide del Bosso Cydalima perspectalis,Walker, 1959 ordine Lepidoptera, 
famiglia Crambidae. Servizio Fitosanitario-Difesa delle colture e delle foreste-Vigilanza e controllo, Servizio Fitosanitario Regionale Via Pietrapiana, 30 - 50121 Firenze. 12p.

Göktürk T (2017) The Effect of Dipel and Spruzit Against Cydalima perspectalis (Walker, 1859) (Lepidoptera: Crambidae), International Forestry and Environment Symposium "Climate Change and Tree Migration" 7-10 November 2017, Abstract Book, p. 125, Trabzon, Turkey.

Hizal E, Kose M, Yesil C, Kaynar D (2012) The new pest Cydalima perspectalis (Walker, 1859) (Lepidoptera: Crambidae) in Turkey. Journal of Animal and Veterinary Advances, 11(3), 400403.

Hrnčić S, Radonjić S (2014) Cydalima perspectalis Walker (Lepidoptera: Crambidae)- nova invazivna štetočina šimšira u Crnoj Gori; 11. Simpozij o zaštiti bilja u Bosni Hercegovini, Teslić, 04-06 November 2014, Godine, Zbornik rezimea, 24-25.

lamandei M (2010) Diaphania perspectalis (Walker, 1859)(Lepidoptera: Crambidae) a new pest of Buxus spp. in Romania. Lucrări Științifice-Universitatea de Științe Agronomice și Medicină Veterinară București. Seria B, Horticultură, (54), 787-793.

Kawazu K, Honda H, Nakamura S Adati T (2007) Identification of sex pheromone components of the box tree pyralid, Glyphodes perspectalis. Journal of Chemical Ecology 33(10): 1978 - 1985.

Kaygın TA, Taşdeler C (2019) Cydalima perspectalis (Walker)(Lepidoptera: Crambidae, Spilomelinae)'in Türkiye'de coğrafi yayılışı, yaşam döngüsü ve zararı. Bartın Orman Fakültesi Dergisi, 21(3), 1-14.

Kaygın TA, Taşdeler C (2018) Cydalima perspectalis (Walker) (Lepidoptera: Crambidae) Şimşirlerimiz için Bir Tehdit mi? III. Türkiye Orman Entomolojisi ve Patolojisi Sempozyumu, Bildiri Özetleri Kitabı, s: 21, 10-12 Mayıs 2018, Artvin.

Koren T, Črne M (2012) The first record of the box tree moth, Cydalima perspectalis (Walker, 1859)(Lepidoptera, Crambidae) in Croatia. Natura Croatica: Periodicum Musei Historiae Naturalis Croatici, 21(2), 507-510.

Korycinska A, Eyre D (2009) Box tree caterpillar, Diaphania perspectalis. FERA Plant pestfactsheet.http://www.fera.defra.gov.uk/plants/plantHealth/pests Diseases/documents/boxTree-Caterpillar.pdf (28.12.2020)

Korycinska A, Eyre D (2011) Box tree caterpillar Cydalima perspectalis. Plant pest factsheet, the Food and Environment Research Agency (Fera) www.defra.gov.uk/fera

Krüger EO (2008) Glyphodes perspectalis (Walker, 1859) - neu für die Fauna Europas (Lepidoptera: Crambidae) Entomologische Zeitschrift 118: 81-83.

Lee S M, Lee D W, Choo HY (1996) Biology and pathogenicity of entomopathogenic nematodes, Steinernema spp., isolated from forest soil in Southern Korea. FRI Journal of Forest Science, Seoul 53: 117-123.

Lehtijärvi A, Lehtijärvi H T, Oskay F (2017) Boxwood blight in Turkey: impact on natural boxwood populations and management challenges. Balt For, 23, 274-278.

Leuthardt F L G, Baur B, (2013) Oviposition preference and larval development of the invasive moth Cydalima perspectalis on five European box-tree varieties. Journal of Applied Entomology, 137 (6): 437-444.

Leuthardt F, Billen W, Baur B (2010) Ausbreitung des Buchsbaumzünslers Diaphania perspectalis (Lepidoptera, Pyralidae) in der Region Basel - eine für die Schweiz neue Schädlingsart. Entomo Helvetica 3: 51-57.

Martin JC, Buradino M, Brinquin AS, Correard M, Thevenet J, Vauthier D, Morel E, Gilli A, Venard M, Tabone E (2018) Reguler la pyrale du buis Cydalima perspectalis: Limites d'utilisation de la pheromone sexuelle de synthese et premiere approche non scientifique de lapredation par les mesanges (Parus spp.) Scientific Symposium on Boxwood Pests, in Tours, France during October, 2018.

Matsiakh I, Kramarets V, Kavtarishvili M, Mamadashvili G (2016) Distribution of invasive species and their threat to natural populations of boxwood (Buxus colchica Pojark) in Georgia. PPT Presentation. National Forestry Agency of Georgia, ENPI East Fleg II Program(https://www.observatree.org.uk/wpcontent/uploads/2016/03/Matsiakh\%20l._Threats\%20to\%20 boxwood\%20in\%20Georgia.pdf)

Matsiakh I, Kramarets V, Mamadashvili G (2018) Box Tree Moth Cydalima perspectalis as a Threat to the Native Populations of Buxus colchica in Republic of Georgia. Journal of the Entomological Research Society, 20(2), 29-42. Retrieved from http://entomol.org/journal/index.php/JERS/article/view/126 2.

Nacambo S, Leuthardt FLG, Kenis M (2013) developmental characteristics of the box-tree moth Cydalima perspectalis and its potential distribution in Europe. Journal of Applied Entomology 138(1-2): 14-26.

Oltean I, Hulujan I, Varga M, Totos Ş, Florian T (2017) Cydalima Perspectalis Walker (Lepidoptera, Crambidae) a New Dangerous Pest Report on Buxus Sempervirens in Cluj Area. Bulletin of University of Agricultural Sciences and Veterinary Medicine Cluj-Napoca. Agriculture, 74 (1): 26-36.

Ostojić, I, Zovko M, Petrović D, Elez D (2015) New records of box tree moth Cydalima perspectalis (Walker, 1859) in Bosnia and Herzegovina. Radovi Poljoprivrednog Fakulteta Univerziteta u Sarajevu (Works of the Faculty of Agriculture University of Sarajevo), 60(65 (1)), 139-143.

Otero RP, Vázquez JPM, Vidal M (2014) Cydalima perspectalis Walker, 1859 (Lepidoptera, Crambidae): una nueva amenaza para Buxus spp. en la Península Ibérica. Arquivos entomolóxicos, (10), 225-228.

Öztürk N, Akbulut S, Yüksel B (2016) Düzce için yeni bir zararlı Cydalima perspectalis (Walker, 1859) (Lepidoptera: Crambidae) Düzce Üniversitesi Ormanclık Dergisi, 12 (1), 112121.

Plant CW, Poole C, Salisbury A, Bird S (2019) The Box-tree Moth Cydalima perspectalis (Walker, 1859) in Britain: an overview of its spread and current status. Entomologist's Record and Journal of Variation, 131, 122-147.

Rose J, Kleespies RG, Wang Y, Wennmann JT, Jehle J A (2013). On the susceptibility of the box tree moth Cydalima perspectalis to Anagrapha falcifera nucleopolyhedrovirus (AnfaNPV) Journal of Invertebrate Pathology, 113 (3): 191-197.

Sáfián S, Horváth B (2011) Box Tree Moth Cydalima perspectalis (Walker, 1859), new member in the Lepidoptera fauna of Hungary (Lepidoptera: Crambidae) Kaposvár, Natura Somogyiensis, 19, 245-246.

Sage W, Karl G (2010) Der Buchsbaumzünsler Cydalima perspectalis (Walker, 1859) nun auch in Südostbayern. Mitteilungen der Zoologischen Gesellschaft Braunau 10(1): 79-85.

Salioğlu Ş (2020) Artvin ili şimşir alanlarında zarar yapan Cydalima perspectalis (Walker, 1859) (şimşir kelebeği)'in morfolojisi, biyolojisi, zararı ve mücadele olanaklarının araştırılması. Yüksek lisans tezi. Artvin Çoruh Üniversitesi, Lisansüstü Eğitim Enstitüsü, Artvin.

Santi F, Radeghieri P, Sigurtà GI, Maini S (2015) Sex pheromone traps for detection of the invasive box tree moth in Italy. Bulletin of Insectology, 68(1),158-160. ISSN 1721-8861. 
Sarı Ö, Çelikel FG (2019) Türkiye'nin Şimşirleri (Buxus sempervirens ve Buxus balearica) ve Mevcut Tehditler. I. International Ornamental Plants Congress - VII.Süs Bitkileri Kongresi, 9-11 Ekim 2019, Bursa, S.383-393.

Seljak G (2012) Six new alien phytophagous insect species recorded in Slovenia in 2011. Acta Entomologica Slovenica, 20, 31-44.

She DS, Feng FJ (2006) Bionomics and control of Diaphania perspectalis (Walker) Journal of Zhejiang Forestry Science and Technology, 26, 47-51.

Sigg CR (2009) Auch das noch: Ein neuer Buchs-Schadling schlagt zu. Massive Schaden durch den Buchsbaumzunsler. Der Gartenbau (Solothurn) 4: 2-4.

Stojanović DV, Konjević A, Marković M, Kereši T (2015) Nalazi šimširovog moljca Cydalima perspectalis (Walker, 1859)(Lepidoptera, Crambidae) u Vojvodini/Appearance of the box tree moth Cydalima perspectalis (Walker, 1859)(Lepidoptera, Crambidae) in Vojvodina. Biljni lekar/Plant Doctor.

Strachinis I, Kazilas C, Karamaouna F, Papanikolau N E, Partsinevolos GK, Milonas P G, (2015) First record of Cydalima perspectalis (Walker, 1859) (Lepidoptera: Crambidae) in Greece. Hellenic Plant Protection Journal 8: 66-72.

Symmes H (1984) Native Stands of Boxwood in Modern Turkey. The Boxwood Bulletin. Boyce, Va. Vol. 23, No.4. Pp. 76-79.
Székely L, Dincă V, Mihai C (2011) Cydalima perspectalis (Walker, 1859), a new species for the Romanian fauna (Lepidoptera: Crambidae: Spilomelinae) Buletin de informare Entomologica, 22(3-4), 73-78.

Trokhov Y, Kaurova Z (2015) Boxwood moth-an invasive species parasite of boxwood groves. XXIV Student International Scientific-Practical Conference "The Scientific Community of Students The XXI Century», V. 8-9 (22), 28-37, 28 October 2014, Novosibirsk, Russia.

Türkyilmaz E (2004) Şimşir (Buxus sempervirens L.) Odununun Bazı Morfolojik ve Fiziksel Özellikleri, V. Ulusal Orman Fakülteleri Öğrenci Kongresi, Bildiriler Kitabı, 2.Cilt-Orman Endüstri Mühendisliği, K.T.Ü. Orman Fakültesi, Trabzon, pp.18-22.

Van der Straten M J, Muus TS (2010) The box tree pyralid (Glyphodes perspectalis (Walker 1859), Lepidoptera: Crambidae); an invasive alien moth ruining box trees. In Proceedings of the Netherlands Entomological Society Meeting, 21, 107-111.

Yıldız Y, Yıldırım I, Bostancı C (2018) Bartın ilinin İstilacı Böcek Türleri, III. Türkiye Orman Entomolojisi ve Patolojisi Sempozyumu, s. 25, 10-12.05.2018. Artvin.

Zhou W, Xia CY, Sun XQ, Zhu B, Liu XP, Liu ZC, Wang Y (2005) Studies on the biological characteristics and control of Diaphania perspectalis Walker. Journal of Shanghai Jiaotong University (Agricultural Science) 23: 52-56. 